\title{
Novel potential of NADPH-oxidase and RHO-kinase pathways inhibition in a genetic in-vitro Parkinson's disease model
}

Ismaila O Ishola ${ }^{1}$, Njedika U Okubadejo ${ }^{2}$, Konrad Klockmeier ${ }^{3}$, Erich E Wanker ${ }^{3}$, Sunday A Omilabu ${ }^{4}$

${ }^{1}$ Department of Pharmacology, Therapeutics and Toxicology, College of Medicine, University of Lagos, Lagos, Nigeria, ${ }^{2}$ Department of Medicine, Neurology Division, College of Medicine, University of Lagos, Nigeria, ${ }^{3}$ Max delbruck Centre for Molecular Medicine, Neuroproteomics division, Berlin, Germany, ${ }^{4}$ Department of Medical Microbiology and Parasitology, College of Medicine, University of Lagos, Nigeria

Introduction: Intracellular $\alpha$-synuclein ( $\alpha$-syn)-rich protein aggregates called Lewy bodies (LB) and neuronal death are present in nearly all cases of sporadic Parkinson disease (PD). It is widely believed that LB appears early in the disease and spreads in synaptically coupled brain networks, driving neuronal dysfunction and death.

Objective: This study examined the effects of telmisartan (angiotensin II receptor type 1 (AT $\left.{ }_{1} \mathrm{R}\right)$ blocker), CGP42112 $\left(\mathrm{AT}_{2} \mathrm{R}\right.$ agonist) and $\mathrm{Y}-27632$ (Rho-associated protein kinase inhibitor) in a genetic in vitro PD model produced by $\alpha$ synuclein in H4 human neuroglioma cell line.

Methods: H4 neuroglioma cells (HTB-148, ATCC) maintained in OPTI-MEM media supplemented with10\% fetal bovine serum, transfected with equimolar ratio of wild-type $\alpha$-synuclein expression constructs (WTSyn) and synphilin-1 (SNCAIP-) or empty vector control, with simultaneous treatment with telmisartan, CGP42112 or Y-27632 (1, 5 or $10 \mu \mathrm{M})$ or telmisartan $(5 \mu \mathrm{M})+\mathrm{Y}-27632(5 \mu \mathrm{M})$ in a 24 well plate.

Results: telmisartan, CGP42112 and Y27632 up to $100 \mu$ M did not affect H4 cell viability (MTT assay). WTSyn-EGFPSynphilin-1 induced marked cell toxicity compared with empty vector control. However, telmisartan or Y-27632 (1, 5 or $10 \mu \mathrm{M})$ produced concentration dependent decrease in toxicity with peak effect (66.92 \pm 8.96 or $46.89 \%$, respectively). CGP42112 $(1,5$ or $10 \mu \mathrm{M})$ produced $(2.03 \pm 0.95,8.52 \pm 2.54$ and $15.87 \pm 4.12 \%$, respectively). Interestingly, synergism was observed in telmisartan $(5 \mu \mathrm{M})+\mathrm{Y}-27632(5 \mu \mathrm{M})$ treated cells producing $86.72 \pm 14.58 \%$ reduction.

Conclusion: Findings from this study showed that telmisartan and Y-27632 attenuates $\alpha$-synuclein pathology. This underscores the translational potential of telmisartan and Y-27632 as disease-modifying drugs for the treatment of PD. 